\title{
CALL FOR PAPERS: STUDENTS’ ATTITUDES TOWARD STATISTICS
}

The Statistics Education Research Journal (SERJ), a journal of the International Association for Statistical Education (IASE), is planning a special issue for November 2012, focused on the topic of Students' Attitudes Toward Statistics. Submission deadlines: Letters of intent by Sept. 30, 2011; Full papers by Dec. 31, 2011. The Guest Editors for this issue are Candace Schau (CS Consultants, LLC, Albuquerque, New Mexico<cschau@comcast.net>) and Michele Millar (Mount Saint Vincent University, Halifax, Nova Scotia < Michele.Millar@msvu.ca $>$ ).

\section{UNDERSTANDING STUDENTS' ATTITUDES TOWARD STATISTICS}

As statistics instructors, we often concentrate on what to teach and how to teach it. In focusing on these aspects of instruction, we sometimes may overlook the fact that some of our students do not like statistics, feel that they cannot understand statistics, think that statistics is worthless, believe that statistics is too difficult to learn, are not interested in statistics, or are not willing to put in the effort needed to learn statistics. That is, some students have negative attitudes toward statistics.

In other disciplines (e.g., mathematics education, psychology), students' academic attitudes are of considerable importance. Many educational models and a great deal of research support the conclusion that students' attitudes toward the discipline are important learning outcomes; in fact, their attitudes are at least as important as subject matter knowledge and skills. When applied to statistics education, these theories and findings from other disciplines suggest that students who leave their statistics courses with negative attitudes are unlikely ever to use what they have learned. That is, they will not intelligently and literately use statistics in their educational, professional, and personal lives.

In statistics education, it is becoming increasingly recognized that attitudes exert a primary impact on students' academic behaviors and are important outcomes in their own right. We forget what we don't use, but attitudes “stick.” Positive attitudes keep us using what we have learned. They also motivate us to seek opportunities to learn more.

Previous issues of SERJ (as well as other journals) have included some articles about students' attitudes toward statistics. These articles often lacked an explicit foundation in educationally-relevant theories, presented results from a small number of students, examined only one or a part of one of the components of students' attitudes toward statistics (e.g., anxiety), and rarely considered the effects of instructors' attitudes. This special issue will focus on investigating students' attitudes toward statistics and their potential causes; we welcome theory-based research using qualitative, quantitative, or mixed research approaches, as well as work that uses primary or secondary data sources.

\section{POSSIBLE TOPICS}

Examples of topics that are relevant for this special issue on Research in Attitudes Toward Statistics include, but are not limited to:

a. Articles that examine/analyze students' and/or instructors' attitudes toward statistics.

b. Articles that investigate changes in attitudes toward statistics.

c. Articles that develop models regarding attitudes toward statistics.

d. Articles on statistical methods for examining attitudes. 
e. Reviews of current research on statistics attitudes.

\section{SUBMISSION GUIDELINES}

Authors are advised to aim for papers in the range of 4000-6000 words of body text (not counting abstract, tables and graphs, references, appendices). Manuscripts for the special issue will be limited to a maximum of 7500 words of body text, but shorter, concise papers are encouraged. All manuscripts will be refereed following SERJ's regular double-blind peer-review process. Manuscripts should be submitted in accordance with SERJ's standard Author Guidelines and using the Template file found on the Journal's website: www.stat.auckland.ac.nz/serj.

\section{DEADLINES AND CONTACT INFORMATION}

Interested authors should send a letter of intent by Sept. 30, 2010, but preferably earlier, consisting of a 150-250 word abstract describing key aspects of the research. This letter should be sent by e-mail to SERJ Guest Editors Candace Schau <cschau@comcast.net> and Michele Millar< expect to get a response within three weeks. Authors wishing to send informal queries regarding the suitability of a planned paper can also contact Candace Schau and Michele Millar.

Full manuscripts must be submitted by Dec. 31, 2011 at the latest to Candace Schau and Michele Millar at the e-mail addresses above, in accordance with the submission guidelines listed earlier.

Decisions about the suitability of proposed papers and the allocation of accepted papers to the special issue or to a regular $S E R J$ issue will be made jointly by the $S E R J$ Editors and Guest Editors. 